\title{
Role of commercial drivers in motor vehicle related injuries in Ghana
}

\author{
Charles Mock, Justice Amegashie, Kwame Darteh
}

\begin{abstract}
Introduction-In many low income countries, commercial vehicles are the major source of motorized transport. Drivers of such vehicles may be an important focus for road safety efforts.

Aims-An estimation of the percentage of motor vehicle related injuries that involved commercial vehicles in Ghana was sought. The knowledge, attitude, and practices of commercial drivers with regards to road safety was then evaluated. Methods-A community based survey was carried out, involving 21105 persons. As well, focus group discussions were held with 30 commercial drivers.

Results-In the survey, 122 motor vehicle related injuries were reported for the preceding year. The majority $(81 \%)$ of these involved commercial vehicles, principally buses $(40 \%)$ and taxis $(24 \%)$. The involvement of commercial vehicles was the same for both motor vehicle crashes $(81 \%)$ and pedestrian injuries $(82 \%)$. However, motor vehicle related injuries in children were especially likely to involve commercial vehicles $(95 \%)$, in comparison with adults $(79 \%)$. The focus groups indicated that commercial drivers had a good general attitude towards road safety. Most believed that actions could be taken that would lower the risk of crashes and injuries, including vision examinations, using seat belts, and avoiding alcohol. However, this knowledge was not fully implemented. For example, few drivers had ever had their vision checked and most used seat belts only for long journeys.
\end{abstract}

Conclusions-In Ghana, commercial drivers are an important group to target in road safety programs. They are also a potentially useful group to include in building coalitions to implement such road safety measures.

(Injury Prevention 1999;5:268-271)

Keywords: trauma; developing country; road safety; commercial driver

Traditionally, infectious disease was the leading cause of mortality world wide. This pattern changed over the past two centuries in industrialized or high income countries (HICs), with decreases in infectious disease and increases in chronic disease and injury. Similar trends are now under way in today's developing or low income countries (LICs). The World Health Organization predicts that by the year 2020, road traffic injuries alone will be the second leading cause of years of life lost for the entire world's population. ${ }^{1-3}$

In HICs, the rate of transport related injury has decreased in recent decades, because of prevention efforts and improved treatment. ${ }^{4}$ However, similar strategies have been poorly addressed in LICs.

In HICs, road safety efforts have primarily targeted drivers of private vehicles, the primary mode of transport. In many LICs, transport patterns are different. There is frequently a greater reliance on public transportation and hence greater importance of commercial drivers.

The purpose of the current study was to estimate the per cent of motor vehicle related injuries that involved commercial vehicles in Ghana. Existing data sources, such as vital statistics registries and police reports, are limited in most LICs. Hence, we undertook a community based survey. We then sought to use focus group discussions to evaluate the knowledge, attitude, and practices of commercial drivers with regard to road safety. We hoped that both components of this study would provide information useful for the development of injury prevention efforts in this and other similar nations.

\section{Methods}

STUDY SETTING

The study setting included an urban and a rural area of Ghana. This nation has a population of 17000000 and a per capita gross national product of $\$ 325$ per year. The urban area studied was the city of Kumasi (population 650 000) and the rural area included all or portions of four contiguous districts of the Brong-Ahafo Region: Berekum, Jaman, Wenchi, and Dormaa (combined population 425 000).

In the study area, the majority of motorized transport is provided by publicly used vehicles, including taxis, minibuses, and buses. Most taxis and minibuses are privately owned and rented to individual commercial drivers. This is also the case for some buses. Many of these are owned by larger companies and by government agencies, however. These companies and agencies usually employ full time commercial drivers.

\section{EPIDEMIOLOGIC SURVEY}

Information on the occurrence of motor vehicle related injuries was obtained from a household interview survey. The survey studied all forms of injury. This paper presents data restricted to motor vehicle related injuries. Methods for the survey have been described in 
prior publications and they are only briefly reviewed here..$^{5-7}$

Persons selected to be interviewed were chosen using two stage cluster sampling. This sampling methodology has been used extensively in LICs, where accurate listings of individual households are not available. ${ }^{8-10}$

In the first stage, subsets of the individual sections (enumeration areas) of Kumasi and of the villages and towns of the rural areas were randomly selected with probability proportional to their populations..$^{8-10}$ In the second stage, research assistants visited each of the selected sites, and selected a random group of households to be interviewed. Information was sought on all individuals living in the selected households.

Information was obtained on any injury during the preceding year that had resulted in one or more days of lost activity. A six page questionnaire was developed specifically for this study, and was orally administered in the vernacular language (Ashanti Twi). This questionnaire concerned the mechanism of injury, the anatomic location, the treatment obtained, cost of treatment, and outcome of the injury. Information was obtained either from the injured person or their relatives, if the injured person was absent or was a child. Ten per cent of sites were randomly chosen and revisited by the principal investigator (CM) to confirm the findings of the field workers for quality assurance purposes. Data gathering was conducted from May to October of 1995. Incidence rates and their $95 \%$ confidence intervals ( $95 \%$ CI) were calculated taking into account the complex multistage sampling strategy. ${ }^{10} 11$

FOCUS GROUP DISCUSSIONS

The setting for the focus groups was the Kejetia Lorry Park in Kumasi. This is a central area in the city where people go to obtain publicly available transportation provided by taxis, minibuses, and buses. It consists of numerous substations, grouped by transport mode (taxi, bus) and destination.

Interviews were conducted in groups of five to seven drivers. Discussions were held at the substation offices. Each group consisted of specific types of drivers, based on type of vehicle driven and destination.

A moderator facilitated the discussions and a recorder listened and took notes. Drivers were asked to discuss their thoughts as to what causes motor vehicle crashes and what can be done to prevent them. They were also asked a series of specific questions about vision, alcohol, fatigue, vehicle maintenance, and seat belts. The questions were open ended and the drivers allowed to give as long an answer as they deemed appropriate.

The drivers were also shown a series of signs and asked to interpret them. These included: sign 1: no overtaking (passing); sign 2: sharp bend ahead; sign 3: pedestrian crossing ahead.

The sessions were conducted in the vernacular language (Ashanti Twi) and lasted one to two hours each. The discussions were tape recorded and the recordings used in the final preparation of the transcripts. The focus groups were conducted in May to July of 1996.

The study was approved by the Ministry of Health of Ghana.

\section{Results}

EPIDEMIOLOGIC SURVEY

The survey addressed all forms of injury. The present study restricts analyses to injuries in which a motor vehicle was involved, including both injuries to occupants and to pedestrians. It excludes pedestrian injuries or bicycle crashes in which no motor vehicle was involved.

Among the households initially approached, $0.6 \%$ refused to participate and $4.1 \%$ had no one home. Data were gathered on a total of 21105 persons living in 431 sites (clusters). The urban sample included 11663 persons in 263 clusters and the rural sample 9442 persons in 168 clusters. During the year before the interview, 122 motor vehicle related injuries were reported. This included 93 in the urban area and 29 in the rural. Of these, eight were fatalities (six urban, two rural). The annual incidence rate of motor vehicle related injuries was $580 / 100000$ (95\% CI 437 to 723$)$ overall. The rate was $800 / 100000$ (95\% CI 572 to 1028) for the urban area and $310 / 100000$ (95\% CI 154 to 466$)$ in the rural area.

The annual motor vehicle related mortality rate was $48 / 100000$ (95\% CI 14 to 83 ) overall. The mortality rate was 67/100 000 (95\% CI 14 to 120) for the urban area and 20/100 000 for the rural area $(95 \% \mathrm{CI}-8$ to 50$)$.

The commercial status of the vehicle involved was known for 108 of the 122 injuries. Among those injuries involving vehicles of known status, 88 (81\%) were commercial vehicles. This varied only minimally by location, with $85 \%$ of injuries associated with commercial vehicles in the urban area and $71 \%$ in the rural area.

The distribution of vehicle types is shown in table 1 . The vehicles that were most commonly involved were buses $(40 \%$, including minibuses) and taxis (24\%). Private vehicles were infrequently involved, whether they were cars $(13 \%)$ or motorcycles $(6 \%)$.

There were moderate variations in per cent involvement of commercial vehicles by age or gender. Of 19 motor vehicle related injuries to children (age <15 years), almost all (95\%) involved commercial vehicles. Of 89 injuries to adults, $79 \%$ involved commercial vehicles. Similarly, of 42 motor vehicle related injuries to

Table 1 Types of vehicles involved in motor vehicle related injuries

\begin{tabular}{ll}
\hline Vehicle & No (\%) \\
\hline Bus & $43(40)$ \\
Taxi & $26(24)$ \\
Truck & $15(14)$ \\
Motorcycle & $4(3)$ \\
$\quad$ Commercial & $6(6)$ \\
$\quad$ Private & $14(13)$ \\
Passenger car (private) & $108(100)^{\star}$ \\
Total &
\end{tabular}

$\star$ Data on vehicle type not available for 14 of the 122 total motor vehicle related injuries. 
females, $88 \%$ involved commercial vehicles. Of 66 injuries to males, $77 \%$ involved commercial vehicles.

The commercial status of the vehicles involved did not vary with the specific mechanism. There were 74 motor vehicle crashes and 34 pedestrian injuries. The per cent involvement of commercial vehicles was $81 \%$ for crashes and $82 \%$ for pedestrians.

Given the preponderance of commercial vehicles, and the high occupancy of these vehicles, $85 \%$ of all persons injured as occupants in motor vehicle crashes were passengers. There were 10 motor vehicle crashes involving private passenger cars for which details were available. Two of these involved collisions with commercial vehicles, and the remainder were single vehicle crashes.

\section{FOCUS GROUPS}

The second component of the study involved the focus group discussions. These were carried out with 30 taxi and minibus drivers, including both those driving exclusively in the city and those driving on interurban and rural roads. The drivers had a median age of 42 years (range 29-56) and had a median of 17 years of driving experience (range 5-36). All of the drivers were men.

\section{Attitude towards road safety}

These discussions indicated that the majority of commercial drivers believed that certain factors increased the risk of crashes and that certain actions could be taken that would lower risk of crashes and injuries. For example, most voiced the opinion that drinking alcohol in any amount could lead to crashes and all denied drinking before driving. They also knew that poor driver vision and poor vehicle maintenance could play a part in crashes. Almost all understood that seat belts could prevent injury in a crash. In general, however, there was an over-emphasis of vehicular factors, with underemphasis on driver behavior as a cause of crashes.

\section{Knowledge and self reported practices}

There were also some important deficits in the drivers' knowledge and in their self reported practices. Despite indicating that good vision is important, few had ever had their vision checked. There seemed to be the belief that only drivers with very poor vision (for example cataracts) would be at increased risk for accidents. There did not seem to be an understanding that most vision problems could be corrected with lenses.

Although almost all drivers indicated they knew the importance of seat belts, most stated that they only used seat belts for long distance journeys.

When, the drivers were shown three basic road safety signs, $36 \%$ were interpreted incorrectly. The sign for "no overtaking (passing)" was interpreted incorrectly $24 \%$ of the time, for "pedestrian crossing ahead" interpreted incorrectly $17 \%$ of the time, and for "sharp bend ahead" interpreted incorrectly $70 \%$ of the time.
Insights

The drivers offered potentially useful insights into the road safety situation in the country. Many spoke of poor relations with vehicle owners and complained of high fees for daily rental of vehicles. Hence, drivers had to spend a large portion of each day driving just to pay the rental fee. This then forced them to work longer hours to secure a profit, which resulted in driving while exhausted.

The drivers also pointed out that many of the imported vehicles did not have seat belts for all occupants and some had no seat belts at all.

Low availability and high cost of good quality spare parts were seen as a contributing factor to poor vehicle maintenance. Many drivers indicated that tires were used until they were completely bald, leading to a high rate of blowouts, which they felt accounted for a significant number of crashes. They also indicated that, because of the cost of brake fluid, some owners and drivers used a soap and water mixture as a substitute.

\section{Suggestions}

Suggestions on how to improve the road safety situation and some impediments to such improvement included:

(1) Increased availability of good quality spare parts. This could be done by relaxing import duties, especially for tires and brake components.

(2) Broken down vehicles left by the roadside are a frequent cause of accidents. There should be more tow trucks available to remove these promptly.

(3) Free or low cost vision testing for drivers should be provided.

(4) Licensing and testing of drivers should be more rigorous.

\section{Discussion}

Road traffic injuries are a leading cause of injury related death and disability in many LICs, including those in Africa, Latin America, and Asia. ${ }^{2}{ }^{12-15}$ Many nations have road safety agencies in place and road safety campaigns ongoing. Several main strategies have been used to combat a variety of risk factors. These include antidrunk driving measures, speed control, vehicle inspection, driver's licensing requirements, promotion of seat belts, and infrastructural changes. ${ }^{16-18}$

Little attention has been directed to the specific role of commercial drivers or to the development of injury prevention efforts targeting them, yet. It would seem reasonable to do so, given the predominance of commercial vehicles in many LICs, especially Africa. In Ghana, 46\% of registered vehicles are commercial (information provided by Vehicle Examination and Licensing Division). Further, due to greater use of commercial vehicles, one would expect there to be many more vehicle miles driven by commercial vehicles. As one indication of this, a recent study in Ghana involved a random, roadside breathalyzer study. ${ }^{19}$ As vehicles were chosen randomly, various types of vehicles would be sampled in proportion to their vehicle 
miles driven. Seventy three per cent of vehicles in this study were commercial. Moreover, commercial vehicles have a higher occupancy than private vehicles. Hence, a far greater proportion of the total person miles traveled is in commercial rather than in private vehicles.

Given the prominence of commercial vehicles in transportation, the goals of the current study were to ascertain their involvement in motor vehicle related injuries in Ghana. The study also sought to provide information that would be useful for injury prevention efforts in this setting. Before drawing conclusions from the data, the limitations of the methodology must be addressed.

\section{LIMITATIONS}

First, the survey relied on self report by respondents. There was no way to independently validate the veracity of their answers. One would expect some tendency to under-report injuries due to memory decay. ${ }^{20}{ }^{21}$ Hence, the incidence and importance of injury is likely to be under-estimated by this study. However, there is no reason to suspect that the proportion of either commercial or private vehicles would be selectively under-reported.

Second, four years have passed since the survey was carried out. The transport safety problem is likely to have gotten gradually worse during that time, as the number of vehicles registered in Ghana continues to grow by about $10 \%$ per year (information provided by Vehicle Examination and Licensing Division).

Third, the focus groups looked at self reported behaviors, which could not be independently validated. One would asssume that the drivers might over-report safer behaviors. For example, all of the drivers denied drinking and driving. However, a prior roadside breathalyzer survey showed that $10 \%$ of taxi drivers and $4 \%$ of bus drivers had blood alcohol concentrations above $80 \mathrm{mg} / \mathrm{dl} .{ }^{19}$ Clearly, there is a discrepancy in the self reported and actual behaviors, as regards at least this one item.

Fourth, the focus groups included taxi and bus drivers but did not include truck drivers, another important group of commercial drivers.

\section{Implications for prevention}

Despite these limitations, the data from this study allow us to make some inferences about the importance of commercial drivers and their potential role in road safety efforts. Vehicles driven by commercial drivers accounted for the large majority of motor vehicle related injuries in this study. This was true for urban and rural locations and for motor vehicle crashes and pedestrian injuries. Children were especially likely to have sustained motor vehicle related injuries from commercial vehicles.

The focus group discussions indicated that commercial drivers were attuned towards road safety issues and understood some of the specific actions that could be taken to lower the risk of crashes and injuries. However, they lacked specific knowledge and often did not implement appropriate behaviors. Such deficits could po- tentially be addressed through licensing requirements and public information campaigns.

The drivers gave some useful insights that might not otherwise be available to road safety officials or to injury prevention researchers. For example, they pointed out the frequent occurrence of driving while exhausted or sleepy from overwork due to economic need. They also pointed out the problems with availability of quality spare parts and the frequent use of less satisfactory alternatives.

Finally, the drivers offered some reasonable suggestions as to ways to improve road safety. These factors indicate that commercial drivers are an important group to target in road safety efforts and to include in building coalitions to implement road safety measures.

We thank Mr nii-Odei of the Ghana Statistical Service for preparation of maps for the survey work; Dr Samuel Forjuoh, Dr Oscar Gish, Dr Ronald Maier, Dr Thomas Koepsell, and Dr Oscar Gish, Dr Ronald Maier, Dr Thomas Koepsell, and Dr
Frederick Rivara for their advice on study design; Mr A Yeboah Frederick Rivara for their advice on study design; Mr A Yeboah
for translation of the questionnaire; and Mr Francis Arthur for for translation of the questionnaire; and Mr Francis Arthur for
assistance with logistics for the field work. We also thank the assistance with logistics for the field work. We also thank the
District Directors of Health Services and/or PHC Coordinators District Directors of Health Services and/or PHC Coordinators
for their help with the field work in each of the rural districts: Dr A Ofosu, Mr F Amponsah, Dr K Yeboah-Antwi, and Dr K A Ofosu, Mr
Antwi-Agyei.

Funded by a grant from the American Association for the Surgery of Trauma.

Presented in part at the Fourth World Conference on Injury Prevention and Control, Amsterdam, 17-20 May 1998.

1 Zwi A. The public health burden of injury in developing countries. Tropical Diseases Bulletin 1993;90:R5-45.

2 Smith GS, Barss P. Unintentional injuries in developing countries: the epidemiology of a neglected problem. Epidemiol Rev 1991;13:228-66.

3 Murray CJ, Lopez A. The global burden of disease. Volume 1: a comprehensive assessment of mortality and disability from Cambridge: Harvard University Press, 1996.

4 Baker SP, O'Neill B, Ginsburg MJ, et al. The injury fact book. 2nd Ed. New York: Oxford University Press, 1992.

5 Mock CN, Forjuoh S, Rivara F. Epidemiology of transportMock CN, Forjuoh S, Rivara F. Epidemiology of transport-
related injuries in Ghana. Accid Anal Prev 1999;31:359-70. 6 Mock CN, nii-Amon-Kotei D, Forjuoh S, et al. EpidemiolMock CN, nii-Amon-Kotei D, Forjuoh S, et al. Epidemiol-
ogy of transportation related injuries in rural Africa. Crash ogy of transportation related injuries in rural
Prevention and Injury Control 1999;1:45-54.

Prevention and Injury Control 1999;1:45-54.
7 Mock C, Maier RV, nii-Amon-Kotei D. Low utilization of formal medical services by injured persons in a developing nation. $\mathcal{F}$ Trauma 1997;42:504-13.

8 Bennett S, Woods T, Liyanage WM, et al. A simplified genral method for cluster-sample surveys of health in developing countries. World Health Stat Q 1991;44:98-106.

9 Henderson RH, Sundaresan T. Cluster sampling to assess immunization coverage: a review of experience with a simplified sampling method. Bull World Health Organ 1982;60: 253-60.

10 Lemeshow S, Robinson D. Surveys to measure programme coverage and impact: a review of the methodology used by the expanded programme on immunization. World Health the expanded program

11 Levy PS, Lemeshow S. Sampling for health professionals. Belmont, California: Lifetime Learning Publications, 1980.

12 Abantanga FA, Mock CN. Childhood injuries in an urban area of Ghana: a hospital based study of 677 cases. Pediatric Surgery International 1998;13:515-18.

13 Arreola-Risa C, Mock CN, Padilla D, et al. Trauma care systems in urban Latin America: the priorities should be prehospital and emergency room management. F Trauma 1995;39:457-62.

4 Elechi EN, Etawo SU. Pilot study of injured patients seen in the University of Port Harcourt Teaching Hospital, Nigeria. Injury 1990;21:234-8.

15 Wu SI, Malison MD. Motor vehicle injuries in Taiwan. Asia Pac f Public Health 1990;4:72-5.

16 Barss P, Smith GS, Baker SP, et al. Injury prevention: an international perspective. New York: Oxford University Press, 1998.

17 Berger LR, Mohan D. Injury control: a global view. Delhi: Oxford University Press, 1996.

18 Forjuoh SN, Li G. A review of successful transport and home injury interventions to guide developing countries. Soc Sci Med 1996;43:1551-60.

19 Mock CN, Amegashie J, Asiamah G. Epidemiology of alcohol impaired driving in an African nation. 42nd Annual Proceedings Association for the Advancement of Automotive Medicine. 1998: 335-51.

20 Mock CN, Koepsell T. Effects of incomplete recall on estimation of annual injury rates in a developing nation. $A m \mathcal{F}$ Epidemiol 1997;145:S35.

21 Coughlin SS. Recall bias in epidemiologic studies. 7 Clin Epidemiol 1990;43:87-91. 